\title{
Tradiciones vs. Bienestar Animal: Propuesta de la juventud a Naciones Unidas
}

María González Lacabex. Licenciada en Derecho y Consultora.

\section{Resumen}

El Postgrado Animales, Derecho y Sociedad y el Research Group ADS de la UAB participaron el pasado mes de abril en una simulación del funcionamiento de la UNESCO, en el marco del Catalonia Model of United Nations (C'MUN 2011). Este documento recoge una valoración general sobre la resolución final acordada en dicho comité sobre el tema "Tradiciones vs. Bienestar Animal", y que será remitida a la Secretaría General de Naciones Unidas como propuesta de jóvenes de todo el mundo a la comunidad internacional.

\section{Palabras clave}

Tradición - Bienestar animal - UNESCO

\section{Abstract}

In April the Postgraduate Degree Animals, Law and Society and the ALS Research Group of the UAB participated at a simulation of the UNESCO's working procedure, within the framework of the Catalonia Model of United Nations (C'MUN 2011). This document summarizes a general evaluation of the final resolution agreed at that commitee on the topic 'Traditions vs. Animal Welfare', and which will be sent to the United Nations Secretary-General as the proposal of the youth of the world for the international community.

\section{Key words}

Tradition - Animal welfare - UNESCO

El pasado mes de abril en Barcelona, el Postgrado Animales, Derecho y Sociedad y el Research Group ADS de la UAB participaron en la 6a edición del Catalonia Model United Nations (C'MUN 2011), en la que 400 jóvenes universitarios de 52 nacionalidades, debatieron y acordaron resoluciones sobre diversos temas de la agenda internacional actual.

María González, Helena Escoda y Carlos Contreras (Postgrado 2011) intervinieron como representantes de Perú, China y Australia, respectivamente, en la simulación realizada para la UNESCO y en la que se abordó el tema: Tradiciones vs. Bienestar Animal ${ }^{1}$.

\footnotetext{
1 Véase noticia publicada en: http://www.derechoanimal.info/esp/page/1504/el-postgrado"animales-derecho-sociedad"-y-el-research-group-ads-de-la-uab-invitados-a-participar-en-la-6o-edicion-de-c'mun-2011
} 
Junto con el resto de conclusiones de los otros comités, la resolución final acordada en materia de Bienestar Animal será enviada a la Secretaría General de Naciones Unidas, de forma que puedan ser tenidas en cuenta como ideario de la juventud de todo el mundo para una mejor gobernanza de la comunidad internacional.

A través de esta resolución ${ }^{2}$, jóvenes de todo el mundo han consensuado disposiciones que resultan sin duda muy favorables a la protección del bienestar animal: reconoce de forma expresa la necesidad de proteger a los animales como seres que sienten, otorga a esta cuestión una relevancia de orden internacional y anima a los gobiernos a adoptar medidas específicas para avanzar en este ámbito.

No obstante, más allá de declaraciones de principios y recomendaciones concretas (que pueden ser muy oportunas y, por tanto, siempre bienvenidas), esta delegación ha echado en falta que el texto ofreciera un pronunciamiento más claro y directo sobre la cuestión que concretamente se planteaba en este comité: Si la UNESCO, de acuerdo con su naturaleza y funciones, debe o no proteger tradiciones que conllevan sufrimiento animal. En este sentido, actualmente existen dos movimientos enfrentados que buscan un reconocimiento internacional que defienda su postura: por un lado encontramos la campaña internacional encabezada por la Sociedad Mundial para la Protección de los Animales, con el objetivo de que las Naciones Unidas aprueben una Declaración Universal sobre Bienestar Animal, y por otro asociaciones internacionales de tauromaquia y peleas de gallos piden a la UNESCO que las declare patrimonio cultural de la humanidad.

Desde su creación en 1945, la misión de la UNESCO consiste en contribuir a la consolidación de la paz, la erradicación de la pobreza, el desarrollo sostenible y el diálogo intercultural mediante la educación, las ciencias, la cultura, la comunicación y la información. Entendemos que la cuestión estribaba en dilucidar si, en el marco de esta misión y de acuerdo con sus objetivos, este organismo debe utilizar los instrumentos de que dispone (en este caso, la declaración de patrimonio de la humanidad) para dotar de salvaguardia internacional a tradiciones en claro conflicto con la protección del bienestar animal. Es decir, si, teniendo en cuenta que la propia Convención para la Salvaguarda del Patrimonio Cultural Inmaterial (2003) reconoce que su aplicación tiene límites, los establecidos por la protección de los derechos humanos y el desarrollo sostenible, ¿podría el bienestar animal constituir también un límite a la consideración de una tradición como "patrimonio cultural inmaterial"?

Éste era, a nuestro juicio, el punto sobre el que esta simulación de la UNESCO debería haber especificado su postura y que, sin embargo, se aborda de una manera superficial e indefinida. Así, a este respecto la resolución se limita a distinguir en sus considerandos entre el sacrificio "por necesidad" y el sacrificio o tortura "por entretenimiento", indicando que este último "debería" ser condenado. Desde la autocrítica, consideramos que este comité debería haber dado un paso más en esta declaración, para concretar en qué se traduce en la práctica. Quizás no se trataba tanto de acordar una declaración general de principios o de lanzar recomendaciones a los Estados, sino de definir cuál es el posicionamiento de la UNESCO en materia de bienestar animal y qué implica dicho posicionamiento para sus propias políticas, programas y actuaciones como organización.

2 Descargar resolución http://www.anue.org/cmun/cmun2011-res-unesco1.pdf 
En cualquier caso, al margen de las consideraciones expuestas sobre el contenido de la resolución final, la participación en el C'MUN 2011 ha resultado una experiencia muy positiva y enriquecedora, tanto por el conocimiento práctico que proporciona sobre el funcionamiento real de un organismo internacional, como por el interesante ejercicio que deben realizar los y las intervinientes a la hora representar intereses generales frente a opiniones individuales. Desde aquí agradecemos a ANUE su invitación y esperamos poder tomar parte en el futuro en iniciativas similares. 